\title{
Ultrasound-Guided Plantar Fascia Release with Needle: A Novel Surgical Technique
}

\author{
A. Iborra1, M. J. Villanueva1, S. L. Barrett ${ }^{2}$ \\ ${ }^{1}$ Institute Avanfi, Madrid, Spain \\ ${ }^{2}$ Innovative Neuropathy Treatment Institute, Glendale, AZ, USA \\ Email: docalvaroiborra@gmail.com
}

Received 30 May 2016; accepted 27 June 2016; published 30 June 2016

Copyright (C) 2016 by authors and Scientific Research Publishing Inc.

This work is licensed under the Creative Commons Attribution International License (CC BY). http://creativecommons.org/licenses/by/4.0/

(c) (†) Open Access

\section{Abstract}

The purpose of this study was to assess the effectiveness of a new procedure, ultrasound-guided partial plantar fasciotomy with needle for plantar fasciosis. Methods: This study was carried out on 16 patients, 9 men and 7 women, with average age 47.5, diagnosed with plantar fasciosis, who were treated through ultrasound-guided partial plantar fasciotomy using multiple perforations. Clinical assessments and ultrasounds of all patients were carried out before treatment, after a week, then after 1, 3 and 12 months. For the clinical assessment the Visual Analogue Scale (VAS) and the Foot and Ankle Disability Index (FADI) were used. Results: There was significant progress at 95\% (Greenhouse-Geisser $p<0.001$ ) of the VAS and the FADI during the study. We had no nerve or other complications: paraesthesia of the entry portal or vascular lesions. Conclusion: Ultrasoundguided partial plantar fasciotomy using multiple perforations is a safe technique, with very satisfactory preliminary results, reducing recovery times and time off work. The technique can be performed in the specialist's consultation room with local anaesthesia, without the need for stitches and with very fast recovery, thus reducing costs. It can be performed on patients with underlying pathology such as diabetes mild to moderate, vascular insufficiency, heart disease or other comorbidities, so this technique could be an improvement on other open plantar fasciotomy surgical techniques.

\section{Keywords}

Fasciitis Plantar, Sonography, Partial Plantar Fasciotomy, Ultrasound-Guided

\section{Introduction}

Plantar fasciitis is the most common cause of lower heel pain. It is estimated that $10 \%$ of the population at some 
point in their lives has had heel pain, although there are few high-quality epidemiological studies available [1].

A study carried out in the USA between 1995 and 2000 found that approximately one million medical appointments were due to pain in the plantar fascia [2].

The incidence of plantar fasciitis is greater among people aged between 40 and 60 , with predominance 2:1 female to male, although it is also common in the athlete population [3]-[5].

It is estimated that it represents $25 \%$ of all lesions in feet in the athlete population, being the most frequent cause of talalgia in this population group [5].

The etiopathogenesis of plantar fasciosis is little known at present. It is believed that biomechanical changes or repeated traumas favour a mechanical overload which can cause microscopic tears of the fascia and an initial inflammatory process which, in the final phases, leads to fibrosis and myxoid degeneration of the collagen tissue, with angiofibrotic hyperplasia, meaning that the more correct term would be plantar fasciosis, rather than plantar fasciitis [6] [7].

When conservative treatments have failed and the lesion has been in place at least 12 months or more, surgery will be indicated, consisting of the partial resection of approximately $40 \%$ of the fascia to minimise the effect of the instability on the arch and maintain the normal biomechanics of the foot [8]-[10].

Surgical procedures to release plantar fasciitis include open surgery, percutaneous release and endoscopic surgery [11]-[17].

Ultrasound-guided or assisted fasciotomy was described by Vohra et al., 2009 [18].

The author did not have direct control, at the same time, of all planes [19].

With the current equipment it is possible to see all planes from the onset of the procedure. We have presented the advancement in this technique performed without tourniquet, with 1 - 2 mm incisions, with local anaesthesia, as an outpatient procedure. This technique is performed in a surgical room [19].

Since 2014 we have modified our surgical approach, performing the ultrasound-guided plantar fasciotomy using multiple perforations with a needle.

The objective of this article is to describe this new ultrasound-guided surgical technique and perform a retrospective review of our clinical results, recovery times and complications. The preliminary clinical results are just as effective as other published techniques but the complications and recovery times are minimal and the costs are hugely reduced, as the procedure can be performed in the consultation room. To the best of our knowledge this is the first description of a non-incisional surgery on the lower limb for plantar fascia.

\section{Materials and Method}

Prospective randomised clinical trial. Evidence level II-III.

This study was carried out on 16 patients, 9 men and 7 women, with an average age of 47.5. All patients were treated using ultrasound-guided partial plantar fasciotomy using multiple perforations.

The data collected to prepare this study was obtained from the clinical history of the patients who attended our centre, the Avanfi Institute.

The inclusion criteria were patients aged between 40 and 60, regardless of sex, who had been suffering from plantar fasciosis in their proximal third for 6 months or more and who had previously undergone conservative treatment. The common practice in our country is to treat patients conservatively for at least 6 months before performing surgery and many of the patients in these series were referred to our Center for other professionals after conservative failed treatments.

The exclusion criteria were all those patients with talalgia who did not meet the diagnostic criteria for plantar fasciosis or who suffered from it but associated with another pathological entity such as nerve entrapment or who had not received conservative treatment for at least 6 months, or who did not meet the inclusion criteria.

Diagnosis was established through the clinic, MRI and ultrasound confirmation using high-resolution equipment (Alpinion E15) with an 8 - $17 \mathrm{MHz}$ multi frequency linear probe. For fasciosis to exist, the thickness has to be greater than $0.4 \mathrm{~cm}$ as described by McMillan in his study, describing a hypoechoic image in the area of the damaged fascia compared to the healthy fascia. Each measurement was repeated three times at each visit, to avoid intraobserver bias (Figure 1) [20] [21].

Other causes of heel pain were ruled out. The patients' condition had progressed for over 8 months and other conservative treatments had failed on all of them and collected by medical records.

All subjects were duly informed of the possibility of carrying out this study and gave their written consent and 


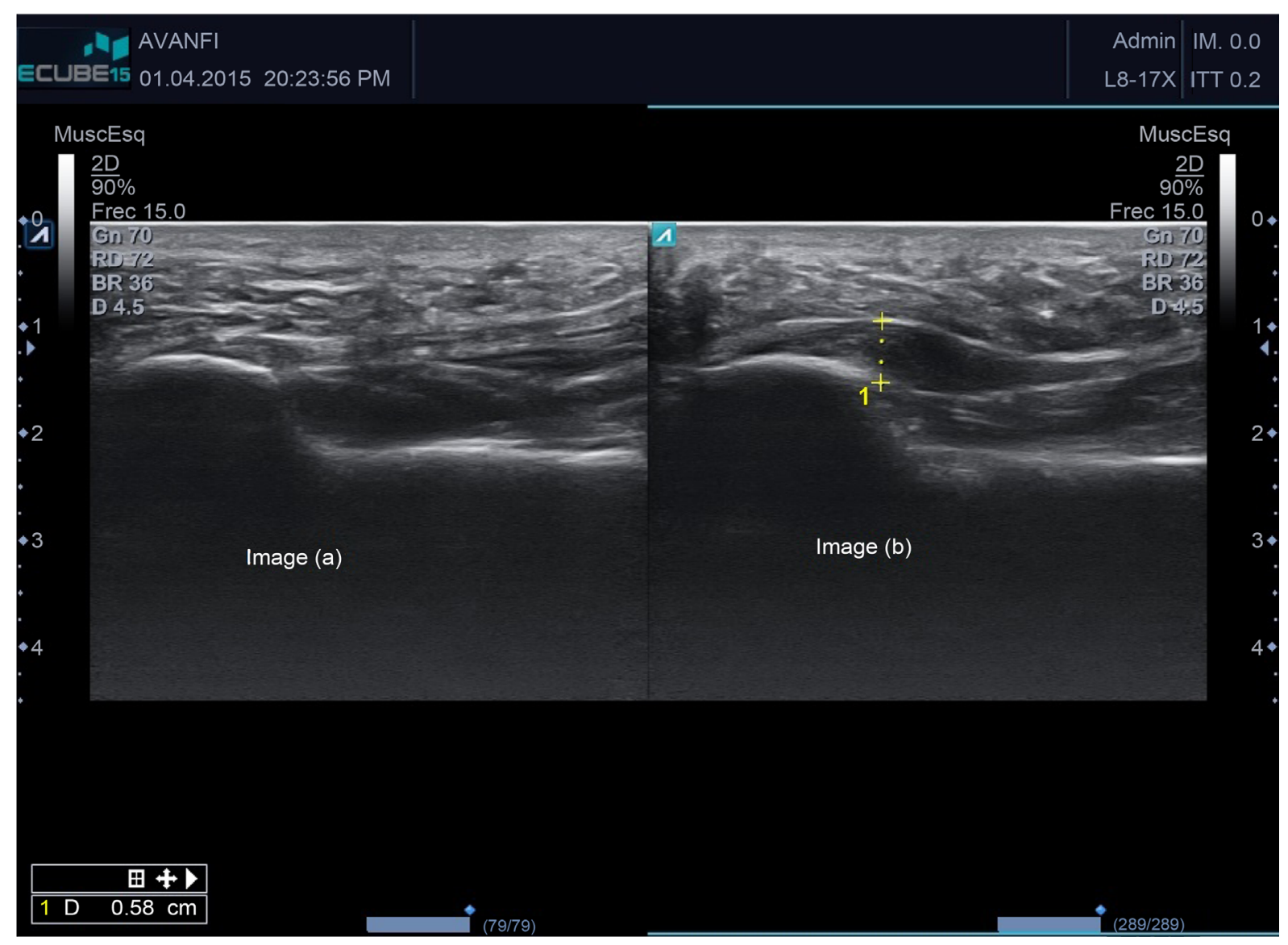

Figure 1. (a) Plantar fascia of normal echogenicity and thickness; (b) Hypoechoic and thickened plantar fascia: $5.8 \mathrm{~mm}$.

commitment, in accordance with the premises laid down in the Helsinki Declaration for research on human subjects.

All patients were under went an ultrasound-guided partial plantar fasciotomy using an Abbocath 16 g needle, from January 2014 to January 2015.

\section{Surgical Technique}

A high-resolution ultrasound machine (Alpinion. E-CUBE 15, with Needle Plus Vision software) and 8 - 17 MHz multi frequency $32 \mathrm{~mm}$ surface contact area linear probe were used.

The patients were laid in a supine position with the affected limb in external rotation and the contralateral leg in hip and knee flexion or also in extension.

The foot was left at the end of the examination table or even over the edge of it, in the air.

The tibial nerve was identified in the ankle and, monitored by ultrasound, was infiltrated using 2 to $3 \mathrm{ml}$ of mepivacaine at $2 \%$ (Scandinibsa ${ }^{\circledR} 2 \%$ ).

An ultrasound sweep was carried out longitudinally and transversally with the objective of determining the entry point of the needle. The point chosen would correspond to the safe point in order not to damage any nerves or vessels and to perform the plantar fasciotomy.

Generally this point usually coincides with the extension of the posterior axis of the tibia and is located just above the epidermal ridges of the heel, on its medial surface, away from the support area. It is usually located at a distance or depth of 1.5 or $2 \mathrm{~cm}$ from the sole, which was determined with an ultrasound measurement taking the interface between the short flexor muscle and plantar fascia as a reference point, up to the cutaneous border (Figure 2).

The surgical field was prepared with sterile material, with the whole foot previously disinfected with povidone-iodine. 


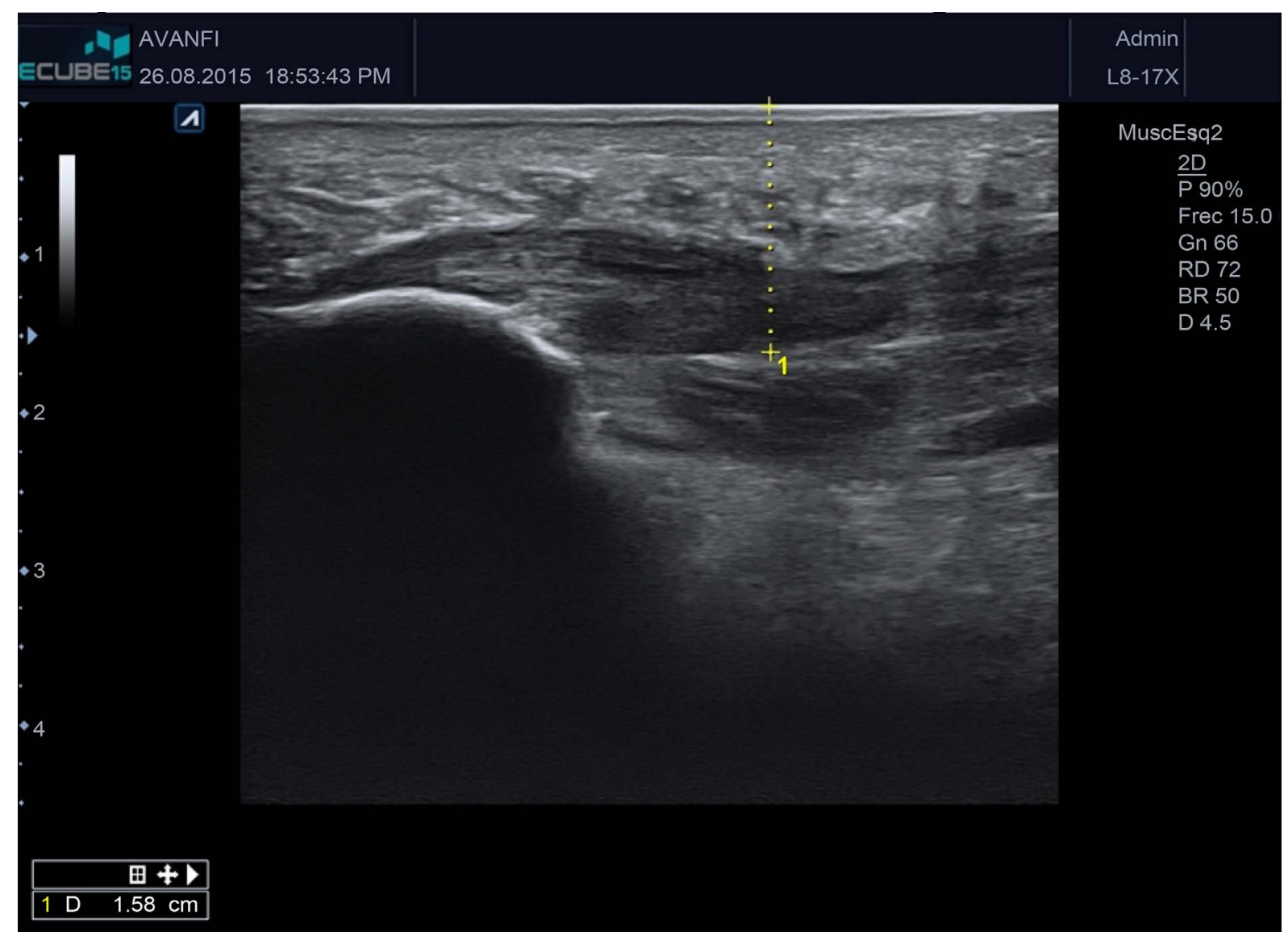

(a)

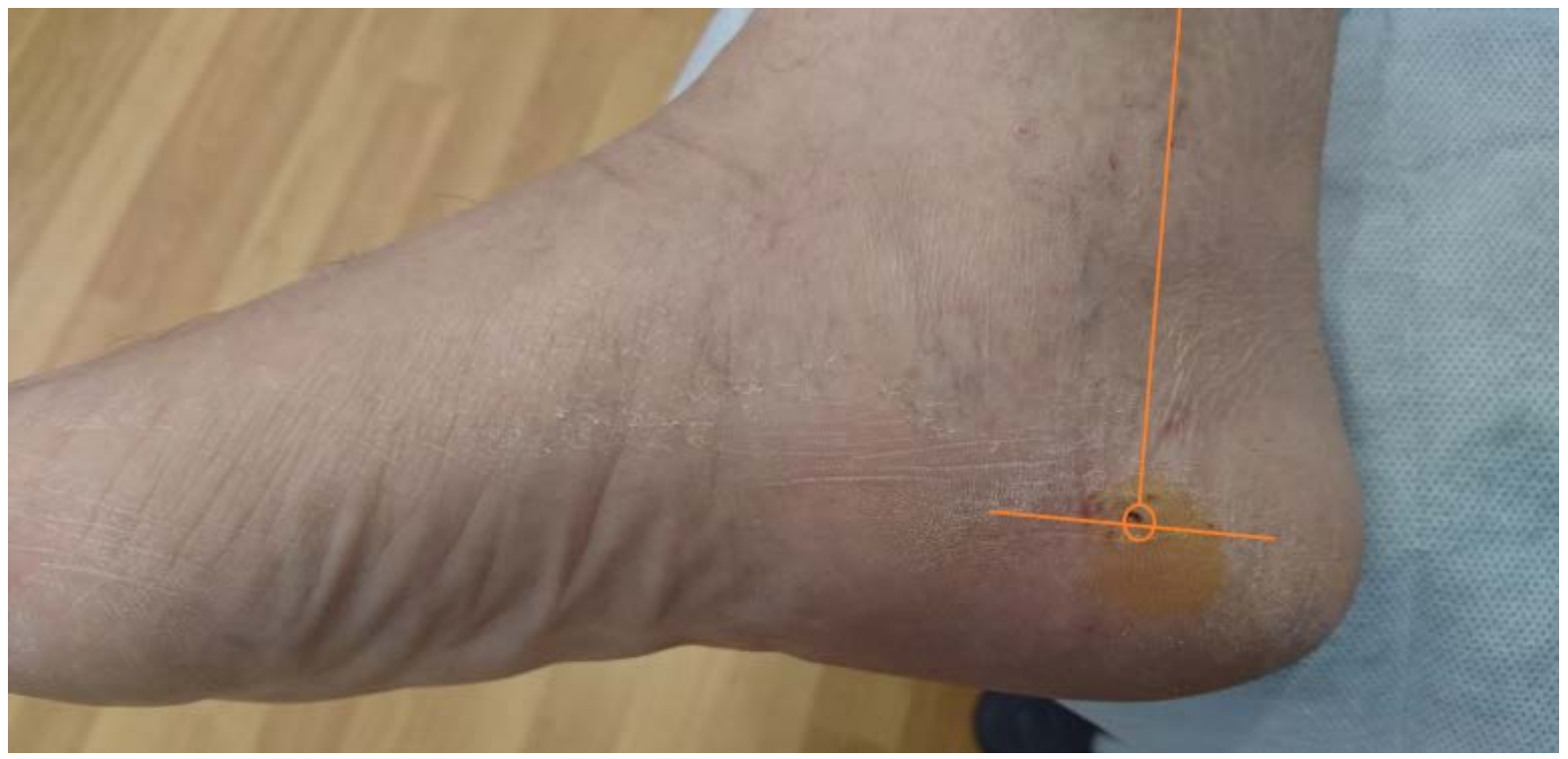

(b)

Figure 2. (a) and (b) Ultrasound measurement of the depth and point of plantar fasciotomy. The entry portal was located where the plantar and dorsal skin of the foot meet.

At the chosen point the $16 \mathrm{G}$ needle was inserted, from medial to lateral, with the transducer situated on the same plane as the needle, in the short or transverse axis to the plantar fascia (Figure 3). 


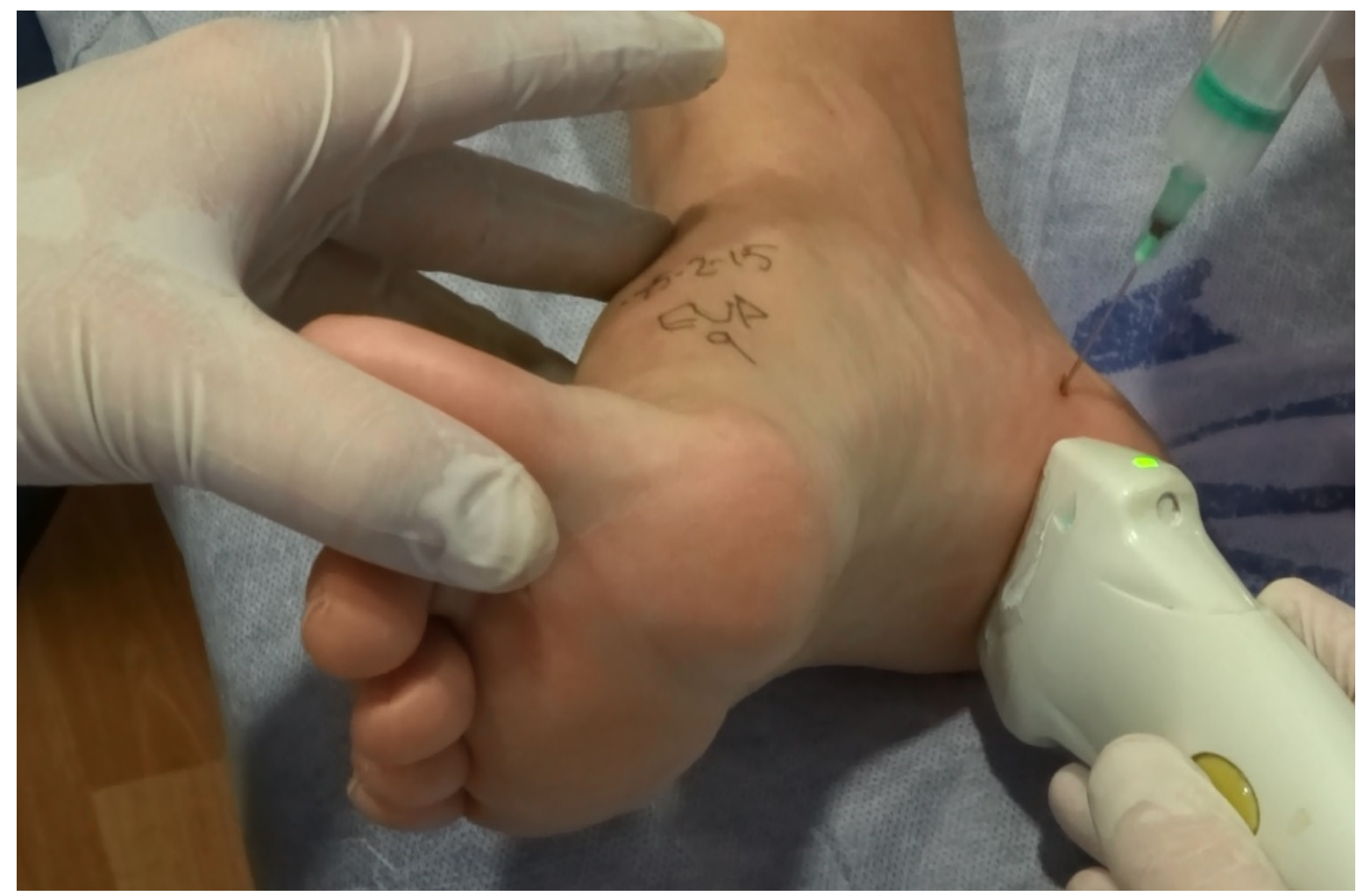

Figure 3. Placing the needle for plantar fasciotomy and the transducer in transversal position.

At all times the procedure was guided by ultrasound to see the point of the needle, the bevel of which was to cut the plantar fascia.

With the ultrasound device in a transverse position, the needle was used to repeatedly perforate the plantar fascia, from medial to lateral and from deep to superficial, always keeping the same plane of perforations, thus obtaining the most linear cut possible and monitoring it at all times via ultrasound, alternating longitudinal and transversal position, preserving the nerves, muscles and talar fat (Figure 4). At the same time as the perforations were being made, a maintained dorsal flexion of the toes and ankle was carried out to tense the plantar fascia. We try to release not more than $50 \%$ of the width of the medial fascicle. These movements were carried out with the utmost care so as not to cause an irregular or excessive tear of the plantar fascia. A continuous monitoring of the needle with the probe in transversal position and critical attention to the position of the tip, is crucial to accomplish this goal.

It is very important to keep the position of the needle and the probe and the plantar fascia tension the same plane throughout the process of multiple perforations, because if the tension is released, the plane the needle was originally in, will be lost, possibly rendering the fasciotomy unsatisfactory.

The procedure lasted between 10 - 15 minutes, until it could be seen, by palpating with the needle and under ultrasound monitoring in transversal and longitudinal position (Figure 4) that the needle easily passed from the most plantar area of the plantar fascia, at its border with the muscle, to the plantar fat, showing that there were no fibres left to cut.

The plantar fascia was infiltrated with $1 \mathrm{ml}$ of bupivacaine at $0.5 \%$ and $2 \mathrm{ml}$ of betamethasone sodium phosphate (Celestone cronodose ${ }^{\circledR}$ ) to reduce inflammation and pain.

The Abbocath was withdrawn and pressure was maintained for 3 - 4 minutes, to favour physiological haemostasis in case of damage to any vessels or muscle fibre. A small adhesive dressing was then placed over the needle entry point (Figure 5), thus ending the procedure, and comfortable footwear, such as a trainer, was put on. The patient left the consultation room walking without the help of crutches.

The patients were instructed to support themselves from the start of the procedure, in order to avoid secondary retractions and adhesions in the plantar fascia. No low molecular weight heparin or antibiotic therapy was administered. 


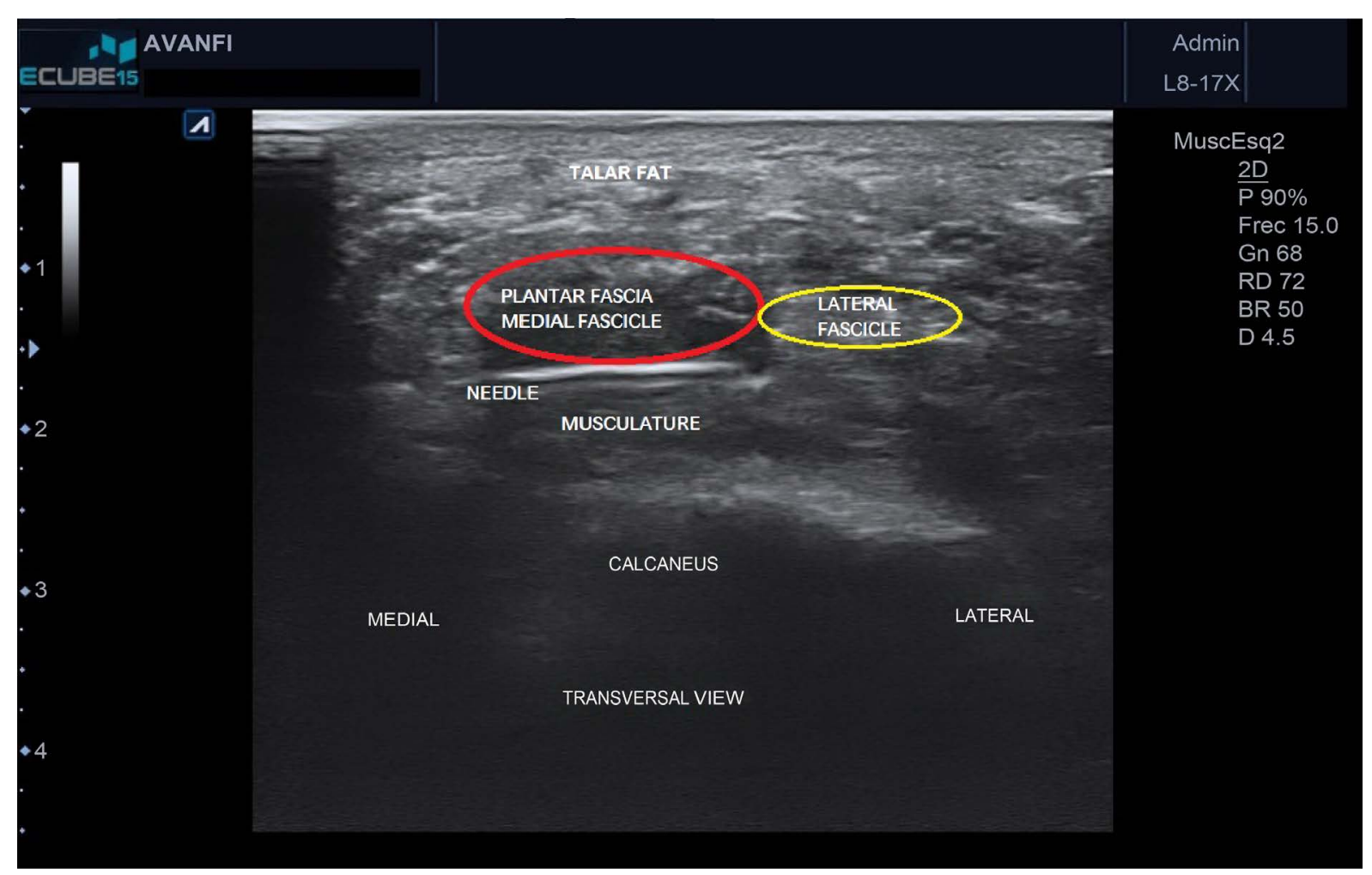

(a)

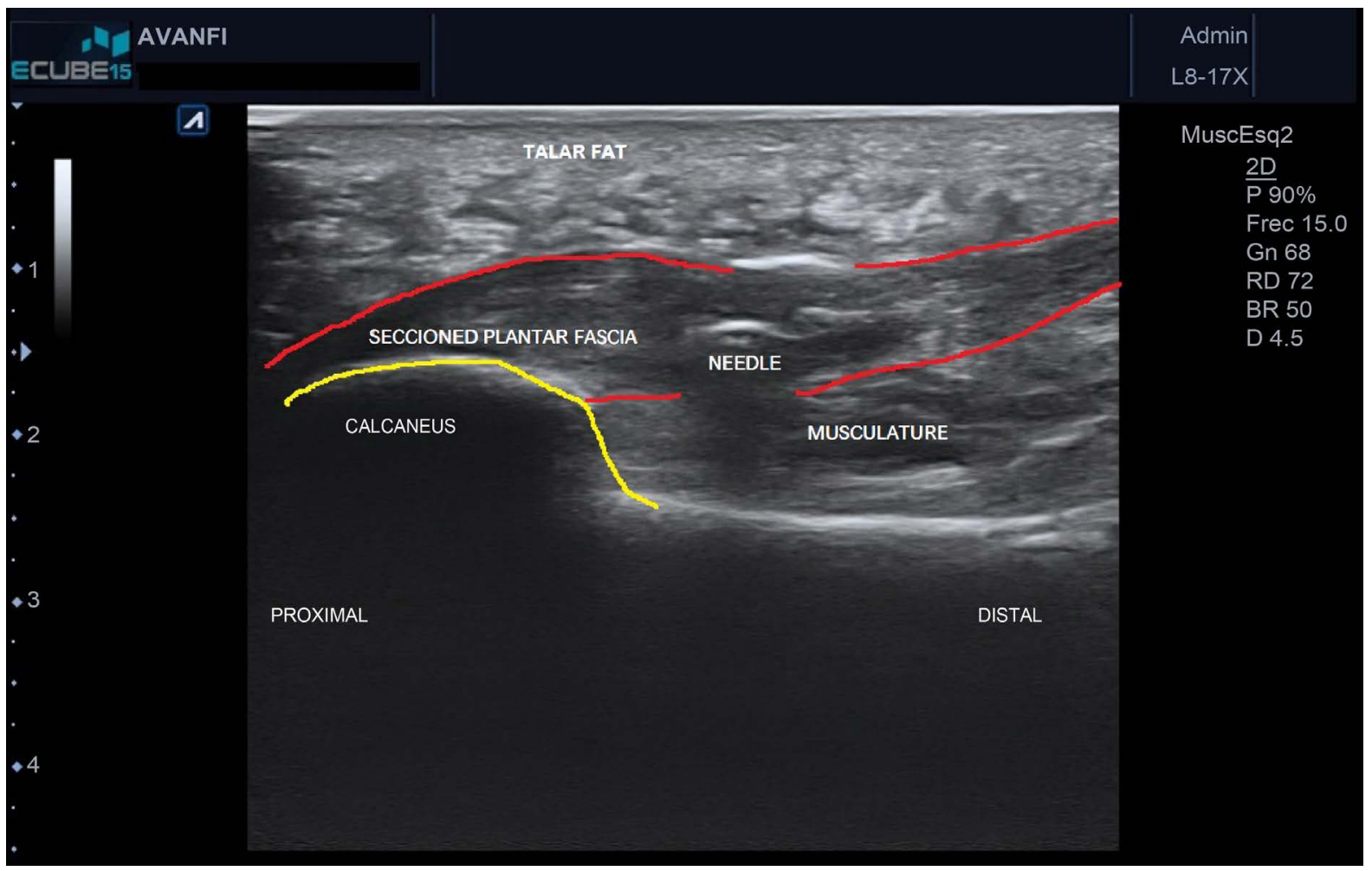

(b)

Figure 4. (a) and (b) Transversal view of the procedure, showing the placement of the needle between the plantar fascia plane and muscles. Longitudinal view of the procedure, showing the placement of the needle in the centre of the plantar fascia and the disruption of its fibres throughout its thickness. We try to release not more than $50 \%$ of the width of the medial fascicle. 


\section{Evaluation of the Results}

Clinical assessments and ultrasounds of all patients were carried out before treatment, after a week, then after 1 , 3 and 12 months (Table 1). For the clinical assessment the Visual Analogue Scale (VAS) (Table 2) and the Foot and Ankle Disability Index (FADI) (Table 3), which assesses function on a scale of 0 - 100, were used [22] [23].

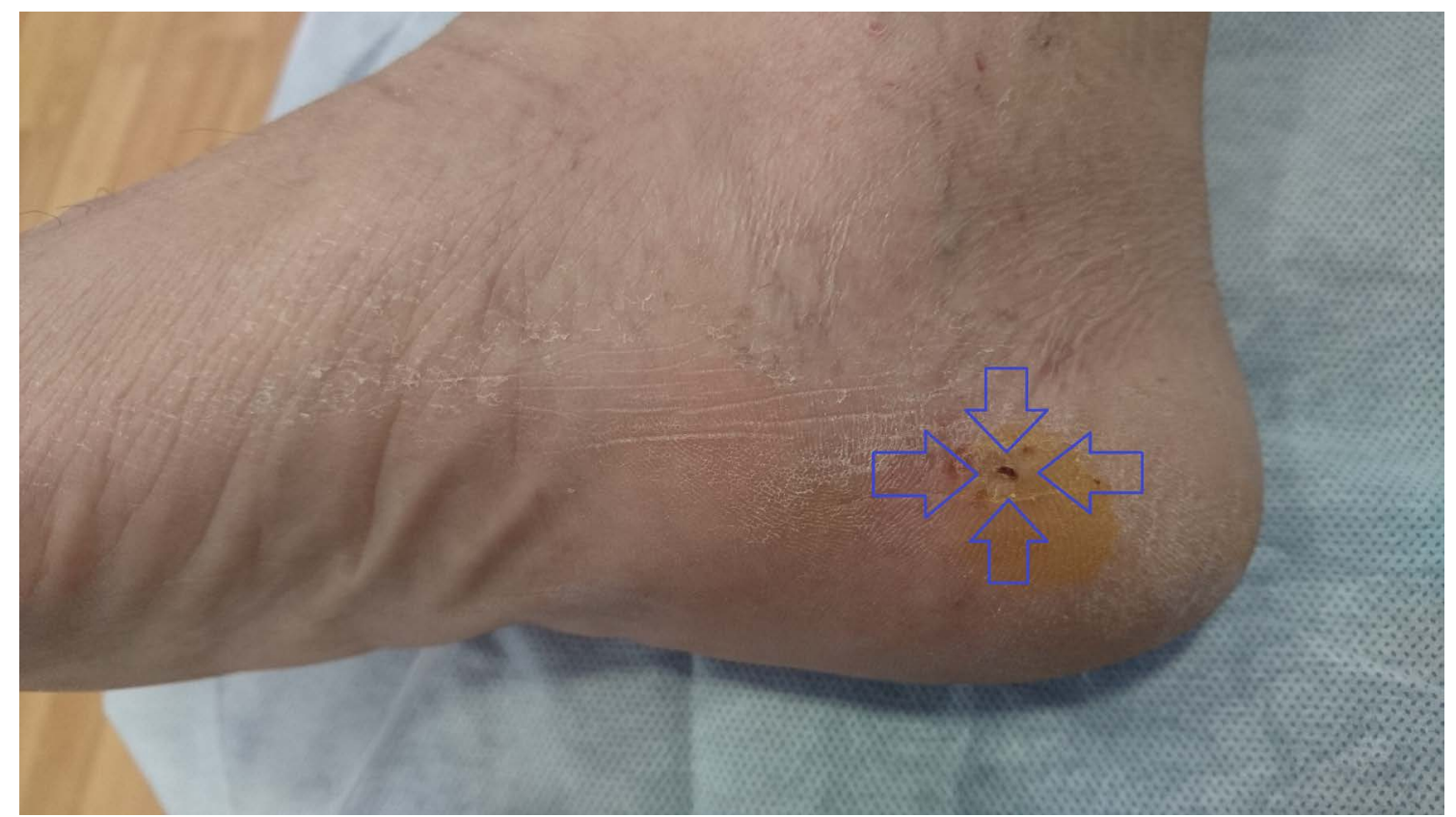

Figure 5. Needle entry and exit point.

Table 1. Plantar fascia thickness.

\begin{tabular}{cccc}
\hline & Mean & Std. deviation & $\mathrm{N}$ \\
\hline Initial thickness & 0.70 & 0.13 & 16 \\
Thickness 1 week & 1.12 & 1.84 & 16 \\
Thickness 3 months & 0.62 & 0.11 & 16 \\
Thickness 12 months & 0.58 & 0.09 & 16 \\
\hline
\end{tabular}

Table 2. VAS.

\begin{tabular}{cccc}
\hline & Mean & Std. deviation & $\mathrm{N}$ \\
\hline Initial VAS & 7.63 & 1.09 & 16 \\
VAS 1 week & 4.69 & 2.33 & 16 \\
VAS 1 month & 2.19 & 1.72 & 16 \\
VAS 3 months & 1.06 & 1.34 & 16 \\
VAS 12 months & 0.63 & 0.89 & 16 \\
\hline
\end{tabular}

Table 3. FADI.

\begin{tabular}{rccc}
\hline & Mean & Std. deviation & N \\
\hline Initial FADI & 42.68 & 14.70 & 16 \\
FADI 3 months & 92.56 & 8.13 & 16 \\
FADI 12 months & 97.19 & 4.61 & 16 \\
\hline
\end{tabular}


For the statistical analysis a repeated measures ANOVA test was performed to see the progress of VAS, FADI and the plantar fascia thickness throughout the study. It was seen that the foot, age, sex, weight, height and body mass index $(\mathrm{BMI})$ factors did not significantly influence $(\mathrm{p}>0.05)$ the progress. The significance which is shown comes from the Greenhouse-Geisser corrected test. The statistical analysis of the data was carried out using the SPSS 22.0 program for Windows.

There is significant progress at 95\% (Greenhouse-Geisser $\mathrm{p}<0.001$ ) of the VAS during the study (Figure 6, Table 2). It can be seen that VAS decreases significantly in all visits compared to the initial score and also compared to the previous visit, except between 3 and 12 months where the decrease is not as significant $(\mathrm{p}=$ 0.069).

The measurement for the plantar fascia thickness was taken before the procedure, after a week, after 3 months and after 12 months.

There is no significant progress at $95 \%$ (Greenhouse-Geisser $\mathrm{p}=0.286$ ) of the thickness throughout the study (Figure 7, Table 1), although if the period from the initial measurement to the measurement taken a week after the procedure is taken in isolation, an increase in thickness can be seen due to tissue inflammation.

The FADI questionnaire was carried out before the technique, 3 months after and 12 months after. There is significant progress at $95 \%$ (Greenhouse-Geisser $\mathrm{p}<0.001$ ) of the FADI during the study (Figure 8, Table 3). It can be seen that FADI increases significantly in all visits compared to the initial score and also compared to the previous visit.

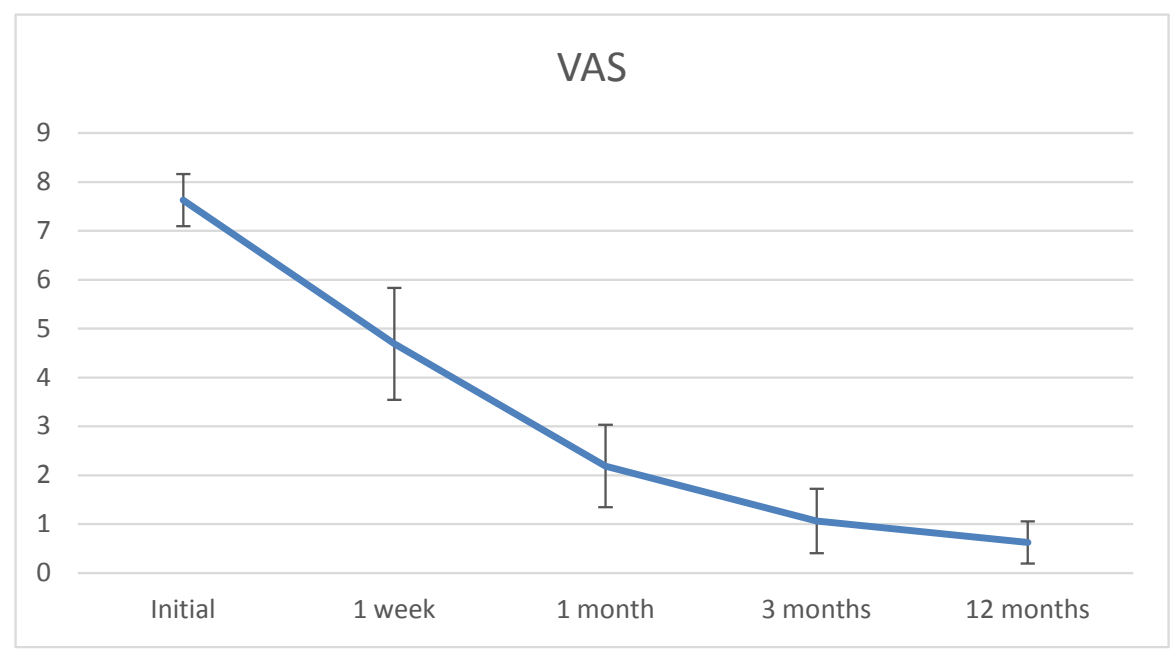

Figure 6. Visual analogue scale (VAS).

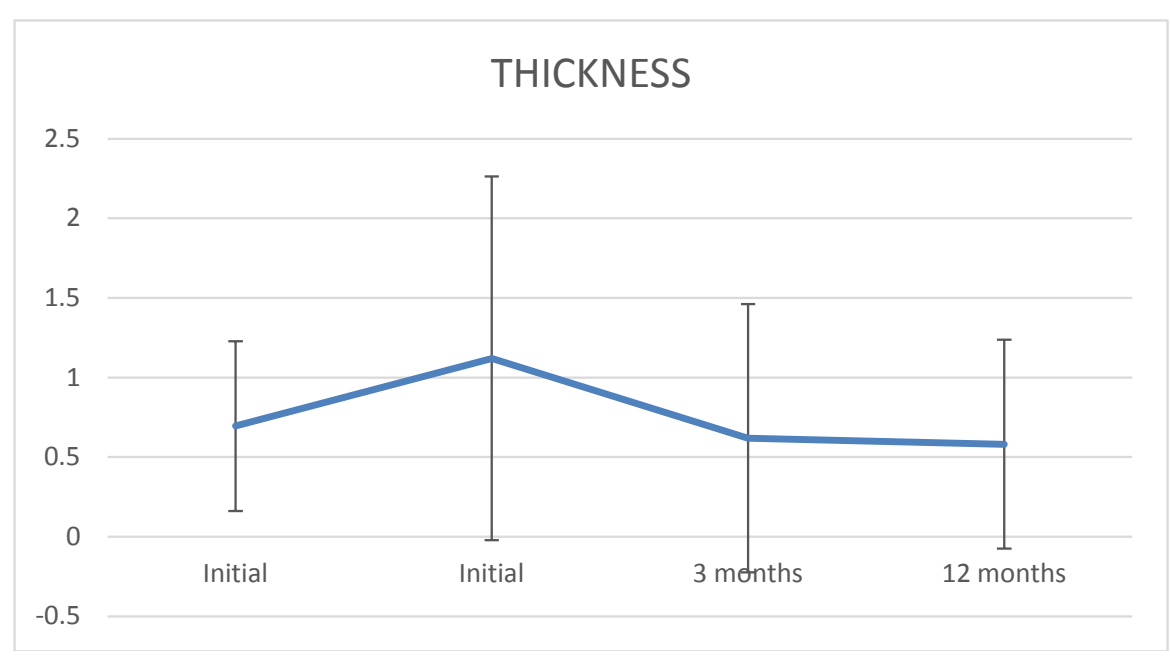

Figure 7. Plantar fascia thickness 


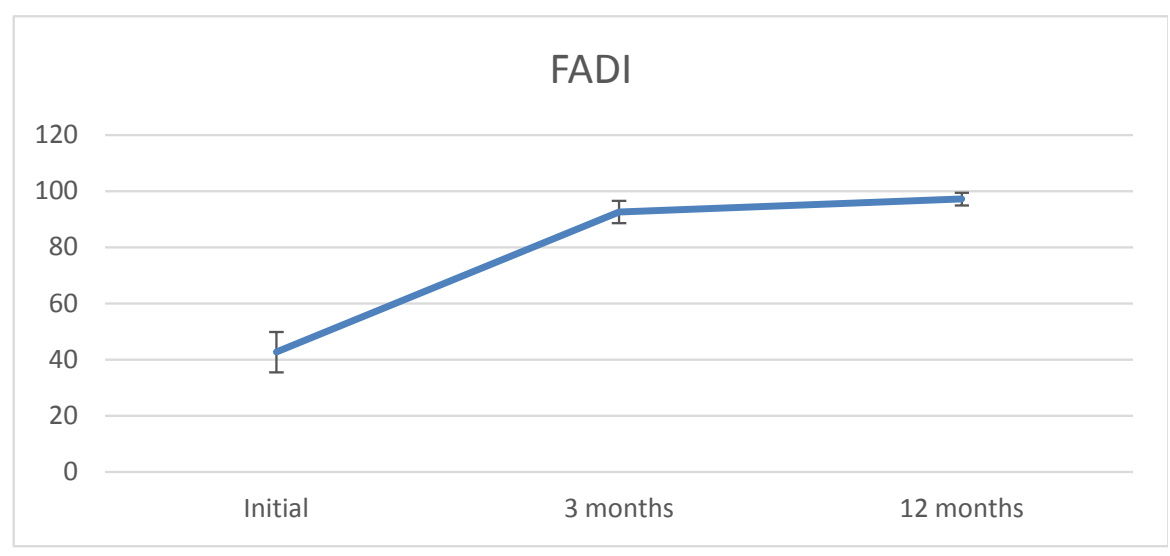

Figure 8. Foot and ankle disability index (FADI).

\section{Discussion}

Plantar fasciitis can generally be treated successfully with conservative measures, obtaining a complete resolution of symptoms and the return to normal activity in $90 \%$ of patients [24]-[27].

Surgical procedures to release plantar fasciitis include open surgery, percutaneous release and endoscopic surgery. These are indicated when the lesion has progressed for more than 3 to 12 months and the conservative treatments have failed [8]-[10] [12] [14]-[17].

Between $10 \%$ - 50\% of patients are not completely satisfied with the results of their surgery, or due to the appearance of complications: residual heel pain, pain in the dorsum of the foot, scar pain or reflex sympathetic dystrophy [9] [15] [16] [28]-[32].

The complications of open surgery are nerve damage, infection, persistent pain or prolonged recovery time. Percutaneous release does not allow the plantar fascia to be viewed; the procedure is done "blind" and the incision is made through the support area, delaying complete support and recovery [33] [34].

Endoscopic partial fasciotomy has increased in popularity in recent years as it offers an improvement on the recovery and complications of open surgery. This technique must be carried out with tourniquet since the bleeding of the tissues will limit the endoscopy image [35] [36].

The main limitation of endoscopic surgery is that the incision is "blind" and the medial portal for this technique has proved to be in close proximity to the posterior tibial nerve and its branches. Barret and others have described neurological complications, such as numbness of the fifth toe or damaging of the lateral plantar nerve, although the incidence rate is very low [12] [35] [37] [38].

To avoid this risk, Ohuchi et al carry out an ultrasound to map the nerves and choose the endoscopy entry portal; in other words they carry out the endoscopy with the assistance of ultrasound. The authors conclude that the biggest advantage of this technique is that it allows the insertion of the endoscope to be guided, avoiding damage to the nerves as it passes through the deep fascia, and it allows the plantar fascia to be viewed dynamically [39].

Ultrasound-guided or assisted fasciotomy was described by Vohra et al., 2009 [18].

The author described a procedure which was carried out with a $5 \mathrm{~mm}$ incision, with ischaemia, in surgery, and in which, probably due to the limited resolution of the equipment used, the authors could not directly monitor all planes, but got to see the deep planes as they released the more superficial ones.

With the current equipment it is possible to see all planes from the start. We have presented an advance in this technique performed without ischaemia, with 1 - $2 \mathrm{~mm}$ incisions, with local anaesthesia, as an outpatient procedure. This technique is performed in a surgical room [19].

In the upper limb McShane described the ultrasound-guided release of the carpal tunnel with an abbocath guided by ultrasound. The technique was carried out in the specialist's consultation room. Although the author described the technique as percutaneous, in reality it is the least invasive way described (without opening up), with direct monitoring of the nerve and adjacent structures [40].

Since 2014 we have modified our surgical approach, performing ultrasound-guided plantar fasciotomy using multiple perforations with a needle. 
This procedure does not require tourniquet, damage to the skin is minimal and it can be performed in the consultation room, as though it were an infiltration, thus avoiding the cost that performing it in an operating room would entail. We believe that it is the first description of a surgery "without opening up" on the lower limb for plantar fascia. The operation is carried out with a real incision smaller than $1 \mathrm{~mm}$, maintaining the bases of our previous work: we do not use tourniquet and only use local anaesthesia, reducing the financial cost.

The ultrasound allows the fascia to be viewed at all times, limiting its release to $40 \%-50 \%$ of the width; other structures can also be viewed, thus avoiding damage to them (Figure 4).

In our series, the VAS and FADI scale values improved significantly, from 7.6 to 0.62 and from $42.6 \%$ to $97.1 \%$ of functionality. The biggest decrease occurred during the first month after the procedure (Table 2 and Table 3).

The plantar fascia thickness decreased during the study, from $6.9 \mathrm{~mm}$ to $5.8 \mathrm{~mm}$, without reaching normal values (Table 1), just as other authors have reported [20] [41].

We had no nerve or other type of complications: paraesthesia of the entry portal or vascular lesions. Some patients had small haematomas which resolved themselves in two weeks.

In our experience, ultrasound-guided partial plantar fasciotomy using multiple perforations is a safe technique, with very satisfactory preliminary results, reducing recovery times and time off work. The technique can be performed on patients with underlying pathology such as diabetes, vascular insufficiency, heart disease or other comorbidities. We believe that such a high success rate is due to the exclusion criteria, as in many cases with chronic talalgia we have seen mixed symptoms with irritation or chronic compression of the plantar branches, which may complicate the prognosis.

However, the technique is operator-dependent, and requires a learning curve and high-resolution equipment to improve the surgical image and precision.

The main limitations of the study are the sample size and the possible population bias, as we have more sporting patients of a high socio-economic level, who might not be representative of the general population. Our strict criteria of inclusion and exclusion may influence our high percentage of good results. However, we believe that in many older patients and those with more comorbidities, causes for surgery to fail could be that they are not pure plantar fasciosis cases, but mixed talalgia symptoms.

A longer follow-up of these patients may reveal the mid-term performance after partial plantar fasciotomy.

Prospective randomised studies are required comparing this technique with other forms of minimally invasive surgery to determine the theoretical advantages and disadvantages of this technique compared to others.

\section{Conclusion}

Ultrasound-guided plantar fasciotomy using multiple perforations with a needle could be better than other surgical plantar fasciotomy techniques, reducing the risks and complications, the hospital costs as the procedure is performed in the specialist's consultation room, and favouring faster patient recovery.

\section{References}

[1] McNally, E.G. and Shetty, S. (2010) Plantar Fascia: Imaging Diagnosis and Guided Treatment. Seminars in Musculoskeletal Radiology, 14, 334-343. http://dx.doi.org/10.1055/s-0030-1254522

[2] Jeswani, T., Morlese, J. and McNally, E.G. (2009) Getting to the Heel of the Problem: Plantar Fascia Lesions. Clinical Radiology, 64, 931-939. http://dx.doi.org/10.1016/j.crad.2009.02.020

[3] Buchbinder, R. (2004) Plantar Fasciitis. New England Journal of Medicine, 350, 2159-2166. http://dx.doi.org/10.1056/NEJMcp032745

[4] Cole, C., Seto, C. and Gazewood, J. (2005) Plantar Fasciitis: Evidence-Based Review of Diagnosis and Therapy. American Family Physician, 72, 2237-2242.

[5] Taunton, J.E., Ryan, M.B., Clement, D.B., McKenzie, D.C., Lloyd-Smith, D.R. and Zumbo, B.D. (2002) A Retrospective Case-Control Analysis of 2002 Running Injuries. British Journal of Sports Medicine, 36, 95-101. http://dx.doi.org/10.1136/bjsm.36.2.95

[6] Wearing, S.C., Smeathers, J.E., Urry, S.R., Hennig, E.M. and Hills, A.P. (2006) The Pathomechanics of Plantar Fasciitis. Sports Medicine, 36, 585-611. http://dx.doi.org/10.2165/00007256-200636070-00004

[7] Lemont, H., Ammirati, K.M. and Usen, N. (2003) Plantar Fasciitis: A Degenerative Process (Fasciosis) without Inflammation. Journal of the American Podiatric Medical Association, 93, 234-237. 
http://dx.doi.org/10.7547/87507315-93-3-234

[8] Urovitz, E.P., Birk-Urovitz, A. and Birk-Urovitz, E. (2008) Endoscopic Plantar Fasciotomy in the Treatment of Chronic Heel Pain. Canadian Journal of Surgery, 51, 281.

[9] Snider, M.P., Clancy, W.G. and McBeath, A.A. (1983) Plantar Fascia Release for Chronic Plantar Fasciitis in Runners. The American Journal of Sports Medicine, 11, 215-219. http://dx.doi.org/10.1177/036354658301100406

[10] Cheung, J.T.M., An, K.N. and Zhang, M. (2006) Consequences of Partial and Total Plantar Fascia Release: A Finite Element Study. Foot \& Ankle International, 27, 125-132.

[11] Barrett, S.L., Day, S.V. and Brown, M.G. (1990) Endoscopic Plantar Fasciotomy: Preliminary Study with Cadaveric Specimens. The Journal of Foot Surgery, 30, 170-172.

[12] Barrett, S.L., Day, S.V., Pignetti, T.T. and Robinson, L.B. (1995) Endoscopic Plantar Fasciotomy: A Multi-Surgeon Prospective Analysis of 652 Cases. The Journal of Foot and Ankle Surgery, 34, 400-406. http://dx.doi.org/10.1016/S1067-2516(09)80011-2

[13] Barrett, S.L. (1994) Endoscopic Plantar Fasciotomy. Clinics in Podiatric Medicine and Surgery, 11, 469-481.

[14] Daly, P.J., Kitaoka, H.B. and Chao, E.Y. (1992) Plantar Fasciotomy for Intractable Plantar Fasciitis: Clinical Results and Biomechanical Evaluation. Foot Ankle, 13, 188-195. http://dx.doi.org/10.1177/107110079201300404

[15] Woelffer, K.E., Figura, M.A., Sandberg, N.S. and Snyder, N.S. (2000) Five-Year Follow-Up Results of Instep Plantar Fasciotomy for Chronic Heel Pain. Journal of Foot and Ankle Surgery, 39, 218-223. http://dx.doi.org/10.1016/S1067-2516(00)80003-4

[16] Lundeen, R.O., Aziz, S., Burks, J.B. and Rose, J.M. (2000) Endoscopic Plantar Fasciotomy: A Retrospective Analysis of Results in 53 Patients. The Journal of Foot and Ankle Surgery, 39, 208-217.

[17] Hogan, K.A., Webb, D. and Shereff, M. (2004) Endoscopic Plantar Fascia Release. Foot \& Ankle International, 25, 875-881.

[18] Vohra, P.K. and Japour, C.J. (2009) Ultrasound-Guided Plantar Fascia Release Technique: A Retrospective Study of 46 Feet. Journal of the American Podiatric Medical Association, 99, 183-190. http://dx.doi.org/10.7547/0980183

[19] Villanueva, M., Iborra, A., Del Carmen, F.B. and De La Rubia, G.A. (2014) Ultrasound-Guided Plantar Fascia Release: A New Ultraminimally Invasive Surgical Technique. AAOS Award Winner, Educational Media, New Orleans 2014. http://www3.aaos.org/product/productpage.cfm?code=V14007

[20] McMillan, A.M., Landorf, K.B., Barrett, J.T., Menz, H.B. and Bird, A.R. (2009) Diagnostic Imaging for Chronic Plantar Heel Pain: A Systematic Review and Meta-Analysis. Journal of Foot and Ankle Research, 2, 32.

[21] Goff, J.D. and Crawford, R. (2011) Diagnosis and Treatment of Plantar Fasciitis. American Family Physician, 84, 676682.

[22] Martin, R., Burdett, R. and Irrgang, J. (1999) Development of the Foot and Ankle Disability Index (FADI). Journal of Orthopaedic \& Sports Physical Therapy, 29, A32-A33.

[23] Orthopaedicscores (2012) The Foot \& Ankle Disability Index (FADI) Score. http://www.orthopaedicscore.com/scorepages/foot_and_ankle_disability_index_fadi.html

[24] Tsai, W.C., Hsu, C.C., Chen, C.P., Chen, M.J., Yu, T.Y. and Chen, Y.J. (2006) Plantar Fasciitis Treated with Local Steroid Injection: Comparison between Sonographic and Palpation Guidance. Journal of Clinical Ultrasound, 34, 1216. http://dx.doi.org/10.1002/jcu.20177

[25] Campbell, R.S.D. and Dunn, A.J. (2012) Radiological Interventions for Soft Tissue Injuries in Sport. The British Journal of Radiology, 85, 1186-1193.

[26] Chen, C.M., Chen, J.S., Tsai, W.C., Hsu, H.C., Chen, K.H. and Lin, C.H. (2013) Effectiveness of Device-Assisted Ultrasound-Guided Steroid Injection for Treating Plantar Fasciitis. American Journal of Physical Medicine \& Rehabilitation, 92, 597-605. http://dx.doi.org/10.1097/PHM.0b013e318278a831

[27] Saxena, A., Fournier, M., Gerdesmeyer, L. and Gollwitzer, H. (2012) Comparison between Extracorporeal Shockwave Therapy, Placebo ESWT and Endoscopic Plantar Fasciotomy for the Treatment of Chronic Plantar Heel Pain in the Athlete. Muscle, Ligaments and Tendons Journal, 2, 312-316.

[28] Bazaz, R. and Ferkel, R.D. (2007) Results of Endoscopic Plantar Fascia Release. Foot \& Ankle International, 28, 549556. http://dx.doi.org/10.3113/FAI.2007.0549

[29] Boyle, R.A. and Slater, G.L. (2003) Endoscopic Plantar Fascia Release: A Case Series. Foot \& Ankle International, 24, 176-179.

[30] Davies, M.S., Weiss, G.A. and Saxby, T.S. (1999) Plantar Fasciitis: How Successful Is Surgical Intervention? Foot \& Ankle International, 20, 803-807. http://dx.doi.org/10.1177/107110079902001209

[31] Jerosch, J., Schunck, J., Liebsch, D. and Filler, T. (2004) Indication, Surgical Technique and Results of Endoscopic 
Release in Plantar Fasciitis. Knee Surgery, Sports Traumatology, Arthroscopy, 12, 471-477. http://dx.doi.org/10.1007/s00167-004-0496-6

[32] Schepsis, A.A., Leach, R.E. and Gorzyca, J. (1991) Plantar Fasciitis: Etiology, Treatment, Surgical Results, and Review of the Literature. Clinical Orthopaedics and Related Research, 266, 185-196. http://dx.doi.org/10.1097/00003086-199105000-00029

[33] Tomczak, R.L. and Haverstock, B.D. (1995) A Retrospective Comparison of Endoscopic Plantar Fasciotomy to Open Plantar Fasciotomy with Heel Spur Resection for Chronic Plantar Fasciitis/Heel Spur Syndrome. The Journal of Foot and Ankle Surgery, 34, 305-311. http://dx.doi.org/10.1016/S1067-2516(09)80065-3

[34] Kinley, S., Frascone, S. and Calderone, D. (1993) Endoscopic Plantar Fasciotomy versus Traditional Heel Spur Surgery: A Prospective Study. The Journal of Foot and Ankle Surgery, 32, 595-603.

[35] Ogilvie-Harris, D.J. and Lobo, J. (2000) Endoscopic Plantar Fascia Release. Arthroscopy: The Journal of Arthroscopic \& Related Surgery, 16, 290-298. http://dx.doi.org/10.1016/S0749-8063(00)90053-7

[36] El Shazly, O., El Hilaly, R.A., El Soud, M.A. and El Sayed, M.N.M. (2010) Endoscopic Plantar Fascia Release by Hooked Soft-Tissue Electrode after Failed Shock Wave Therapy. Arthroscopy: The Journal of Arthroscopic \& Related Surgery, 26, 1241-1245. http://dx.doi.org/10.1016/j.arthro.2010.01.026

[37] Manske, M.C., McKeon, K.E., McCormick, J.J., Johnson, J.E. and Klein, S.E. (2016) Arterial Anatomy of the Posterior Tibial Nerve in the Tarsal Tunnel. The Journal of Bone \& Joint Surgery, 98, 499-504. http://dx.doi.org/10.2106/JBJS.15.00787

[38] Komatsu, F., Takao, M., Innami, K., Miyamoto, W. and Matsushita, T. (2011) Endoscopic Surgery for Plantar Fasciitis: Application of a Deep-Fascial Approach. Arthroscopy: The Journal of Arthroscopic \& Related Surgery, 27, 1105-1109. http://dx.doi.org/10.1016/j.arthro.2011.02.037

[39] Ohuchi, H., Ichikawa, K., Shinga, K., Hattori, S., Yamada, S. and Takahashi, K. (2013) Ultrasound-Assisted Endoscopic Partial Plantar Fascia Release. Arthroscopy Techniques, 2, e227-e230. http://dx.doi.org/10.1016/j.eats.2013.02.006

[40] McShane, J.M., Slaff, S., Gold, J.E. and Nazarian, L.N. (2012) Sonographically Guided Percutaneous Needle Release of the Carpal Tunnel for Treatment of Carpal Tunnel Syndrome Preliminary Report. Journal of Ultrasound in Medicine, 31, 1341-1349.

[41] Liang, H.W., Wang, T.G., Chen, W.S. and Hou, S.M. (2007) Thinner Plantar Fascia Predicts Decreased Pain after Extracorporeal Shock Wave Therapy. Clinical Orthopaedics and Related Research, 460, 219-225.

\section{Submit or recommend next manuscript to SCIRP and we will provide best service for you:}

Accepting pre-submission inquiries through Email, Facebook, Linkedin, Twitter, etc

A wide selection of journals (inclusive of 9 subjects, more than 200 journals)

Providing a 24-hour high-quality service

User-friendly online submission system

Fair and swift peer-review system

Efficient typesetting and proofreading procedure

Display of the result of downloads and visits, as well as the number of cited articles

Maximum dissemination of your research work

Submit your manuscript at: http://papersubmission.scirp.org/ 